Thermodynamic and kinetic characterization of pH-dependent interactions between bovine serum albumin and ibuprofen in 2D and 3D systems E. Csapó ${ }^{1, *}$, Á. Juhász ${ }^{1}$, N. Varga ${ }^{2}$, D. Sebők ${ }^{2}$, V. Hornok ${ }^{2}$, L. Janovák ${ }^{2}$, I. Dékány ${ }^{1, *}$

Graphical abstract

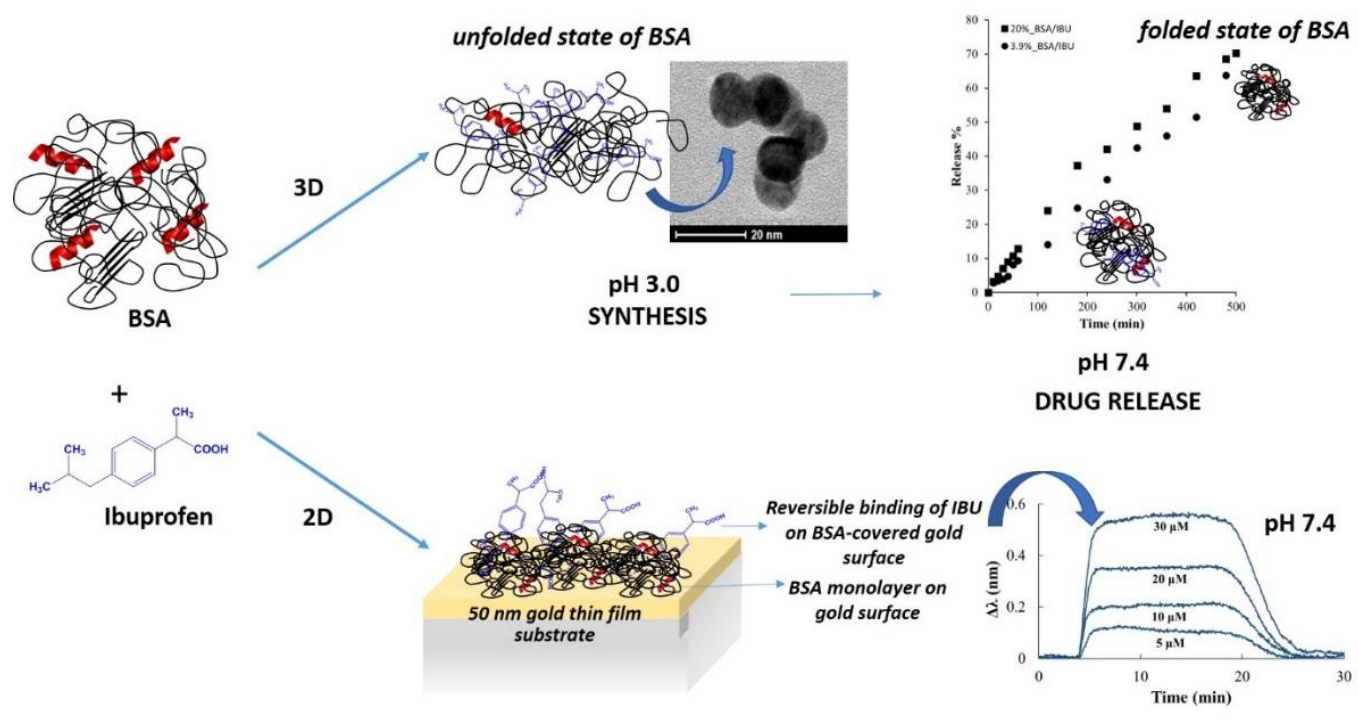

(not proportional representation) 


\section{Thermodynamic and kinetic characterization of pH-dependent interactions between bovine serum albumin and ibuprofen in 2D and 3D systems}

E. Csapó ${ }^{1, *}$, Á. Juhász ${ }^{1}$, N. Varga ${ }^{2}$, D. Sebők ${ }^{2}$, V. Hornok ${ }^{2}$, L. Janovák ${ }^{2}$, I. Dékány ${ }^{1, *}$

\section{Highlights}

- Design of BSA-IBU NPs was carried out by the results of several 2D and 3D experiments

- The pH-induced structural changes of BSA were proven in 2D and 3D systems

- Quantitative data of the BSA-IBU interactions were presented at different $\mathrm{pH}$

- Kinetic constants and thermodynamic state functions were determined by SPR and ITC

- The $\mathrm{pH}$-induced ibuprofen release of the nanosized composite particles was confirmed 


\title{
Thermodynamic and kinetic characterization of pH-dependent interactions between bovine serum albumin and ibuprofen in 2D and 3D systems
}

\author{
E. Csapó $^{1, *}$, Á. Juhász ${ }^{1}$, N. Varga ${ }^{2}$, D. Sebők ${ }^{2}$, V. Hornok ${ }^{2}$, L. Janovák ${ }^{2}$, I. Dékány ${ }^{1, *}$
}

\begin{abstract}
${ }^{1}$ MTA-SZTE Supramolecular and Nanostructured Materials Research Group, University of Szeged, Department of Medical Chemistry, Faculty of Medicine, H-6720 Dóm tér 8, Szeged, Hungary

${ }^{2}$ Department of Physical Chemistry and Material Sciences, University of Szeged, H-6720 Aradi Vt. tere 1, Szeged, Hungary
\end{abstract}

\begin{abstract}
*Corresponding authors at: MTA-SZTE Supramolecular and Nanostructured Materials Research Group, University of Szeged, Hungary, E-mail addresses: tidecs2000@yahoo.co.uk (E. Csapó), i.dekany@chem. u-szeged.hu (I. Dékány) Tel: +36(62)544210, Fax: +36(62)544042
\end{abstract}

\begin{abstract}
The interactions between bovine serum albumin (BSA) and ibuprofen (IBU) were investigated at $\mathrm{pH} 3.0$ and $\mathrm{pH} 7.4$ by several two-(2D) and three-(3D) dimensional techniques to provide quantitative, kinetic and thermodynamic data on the BSA-IBU binding. Based on the results, the preparation of BSA-IBU composite nanoparticles (NPs) were successfully carried out for controlled drug release. The high resolution transmission electron microscopy (HRTEM), dynamic light scattering (DLS) and small angle x-ray scattering (SAXS) studies confirm the formation of nearly monodisperse NPs with $d_{\text {average }}=10-13 \mathrm{~nm}$ depending on the protein concentrations and IBU contents. The kinetics of $\mathrm{pH}$-induced drug release was studied by a vertical diffusion cell at $\mathrm{pH} 7.4$ at $25{ }^{\circ} \mathrm{C}$. The $\mathrm{pH}$-dependent changes in the secondary structure of BSA were proven by SAXS, DLS and surface plasmon resonance (SPR) investigations. Depending on the protein conformations, the SPR results suggest that the bonded amounts of the drug molecule are $1239 \mathrm{mg} \mathrm{IBU/g} \mathrm{BSA}$ and $174 \mathrm{mg}$ IBU/g BSA at acidic and neutral $\mathrm{pH}$, respectively. Besides quantification of the interactions, the rate of association $\left(k_{a}\right)$ and dissociation $\left(k_{d}\right)$, the $K_{A}$ and $K_{D}$ standard equilibrium constants and the binding free energy $\left(\Delta G^{\circ}\right)$ were also calculated on the basic of SPR measurements. The $\Delta G^{\circ}=$ $-21.5 \pm 0.2 \mathrm{~kJ} \mathrm{~mol}^{-1}$ obtained by SPR in $2 \mathrm{D}$ system is in good agreement with the $\Delta G^{\circ}=-$ $17.38 \pm 0.54 \mathrm{~kJ} \mathrm{~mol}^{-1}$ determined by isotherm titration calorimetry (ITC) in solution (3D).
\end{abstract}


Keywords: thermodynamics, kinetic studies, BSA, ibuprofen, nanocomposite

\section{Introduction}

Nanoscale drug delivery systems have been under investigations for several decades [1-3]. At present, numerous types of NPs are designed as feasible candidates for gene therapy and molecular imaging [4], but only very few have actually to mature to clinical applications. Polymer-, dendrimer-, lipid-, iron oxide-, quantum dots- or other organic- and inorganic-based NPs are synthesized in order to deliver a drug to the right place at the right time in adequate concentration [5-8]. The proteins are also widely used for encapsulation and transportation of different drug molecules. The albumin-(BSA or HSA)-based NPs play a determinant role in the development of novel nanocarrier systems because many binding sites are available to several drug molecules. Moreover, the albumins have various specific advantages in nanoscale range, such as biodegradability, biocompatibility and non-toxicity [8]. In the interest of the development of an effective drug delivery systems the interaction between the drug and the carrier should be strong enough to facilitate the transport but also weak enough to release the drug to the target. Thus, the quantitative study of the binding thermodynamics and the knowledge of the kinetics of the release process are necessary [9]. Contrary to the (radio)labelled techniques in recent years a number of "label-free" techniques have been developed to report biomolecular interactions [10-12]. Two-dimensional SPR is a label-free technique and capable of measuring real-time quantitative binding affinities and kinetics for proteins interacting with biomolecules using relatively small (in nanomolar range) quantities of materials and has potential to be medium-throughput [13-15]. The conventional SPR technique requires that one binding component to be immobilised on a sensor chip while the other binding component in solution is flowed over the sensor surface; a binding interaction is detected using an optical method that measures remarkably small changes in refractive index at the sensor surface. By using this biosensor assay not only quantitative and kinetic information can be obtained, but the thermodynamic state functions of the interactions as well $[16,17]$ because the experiments are carried out at different temperatures.

In the present work, BSA-IBU composite NPs were prepared at $\mathrm{pH} 3.0$ for $\mathrm{pH}$-induced controlled drug release and kinetics of the ibuprofen release process at $\mathrm{pH} 7.4$ was studied in in vitro experiments. Since the preparation of composite NPs was carried out at $\mathrm{pH} 3.0$ and the drug release was measured at $\mathrm{pH} 7.4$ the interactions between the protein and drug molecule were investigated at the above mentioned two $\mathrm{pH}$ values by using several $2 \mathrm{D}$ and $3 \mathrm{D}$ techniques in order to provide deeper information on the binding and release processes. 
SPR and SAXS measurements were carried out to study the size and the structure of the nanosized particles and to determine the binding capability of protein at different $\mathrm{pH}$. The thermodynamic binding constant $\left(K_{b}\right)$, the state functions $\left(\Delta G^{\circ}, \Delta H^{\circ}, \Delta S^{\circ}\right)$ and also the stoichiometry of the interaction $(n)$ were determined by ITC [18], while the rate of association and dissociation and the $\mathrm{K}_{\mathrm{A}}$ and $\mathrm{K}_{\mathrm{D}}$ standard equilibrium constants were calculated by fitting of the SPR sensorgrams. The calculated kinetic constants obtained by SPR in 2D systems were compared with the results of the IBU release process measured in aqueous solution (3D).

\section{Materials and Methods}

\subsection{Materials}

All chemicals and solvents were of analytical grade and were used without further purification. The BSA (fraction V), the IBU $\left(\mathrm{C}_{13} \mathrm{H}_{18} \mathrm{O}_{2}\right)$ and the components of the McIlvaine's buffer ( $\mathrm{pH}$ 3.0) and the phosphate buffer (PBS, $\mathrm{pH}$ 7.4) were purchased from Sigma Aldrich, the sodium chloride $(\mathrm{NaCl})$, the sodium sulphate $\left(\mathrm{Na}_{2} \mathrm{SO}_{4}\right)$, the sodium hydroxide $(\mathrm{NaOH})$ and the hydrogen chloride $(\mathrm{HCl})$ from Molar Chemicals. The stock solutions were freshly prepared, using Milli-Q ultrapure water $\left(18.2 \mathrm{M} \Omega \mathrm{cm}\right.$ at $\left.25^{\circ} \mathrm{C}\right)$.

\subsection{Preparation of BSA-IBU nanocomposite particles}

The studied nanosized protein-non steroidal anti-inflammatory (NSAID) composites were prepared according to the procedure published previously [19,20]. Briefly, $20 \mathrm{w} / \mathrm{v} \%$ BSA was dissolved in $15 \mathrm{ml}$ buffer solution (McIlvaine buffer, $\mathrm{pH}$ 3.0). When it completely dissolved IBU molecules were added to the BSA solution with continuous stirring in 1:1 and 1:10 molar ratios. We have stirred the solution for two additional hours at room temperature in order to form the BSA-IBU nanocomposites since more and more drug binding results more and more dissolved drug molecules. The BSA-IBU NPs were precipitated by $2 \mathrm{M} \mathrm{Na}_{2} \mathrm{SO}_{4}$. The product was obtained by freeze drying (lyophilized) after centrifugation (15000 rpm, $15 \mathrm{~min}$ ).

\subsection{HRTEM, DLS and SAXS measurements}

HRTEM images were taken by a FEI Tecnai $G^{2} 20$ X-TWIN microscope with tungsten cathode at $200 \mathrm{kV}$. The parallel DLS measurements were performed with a Horiba, Nanopartica SZ-100 Nanoparticle Analyzer (He-Ne laser with $532 \mathrm{~nm}$ wavelength) in order to determine the size of NPs. Small angle X-ray scattering (SAXS) were used to analyze the morphology, size and inner structure of the prepared composites and also to study the 
conformation change of BSA at acidic and neutral $\mathrm{pH}$ values. SAXS curves were recorded with a slit-collimated Kratky compact small-angle system (KCEC/3 Anton-Paar KG, Graz, Austria) equipped with a position-sensitive detector (PSD 50M from M.Braun AG. Munich, Germany). $\mathrm{Cu} \mathrm{K} \alpha$ radiation was generated by a Philips PW1830 X-ray generator operating at $40 \mathrm{kV}$ and $30 \mathrm{~mA}$.

\subsection{SPR investigations}

SPR measurements were carried out to determine the size and the orientation of BSA adsorbed on the gold chip, and the binding capability of IBU on the BSA-functionalized gold surface at $\mathrm{pH} 3.0$ and $\mathrm{pH}$ 7.4. A two-channel SPR sensor platform developed at the Institute of Photonics and Electronics (Prague) was used. The SPR chip is a thin gold layer (50 nm thick) deposited on a glass substrate. During investigations, a flow rate of $25 \mu 1 \cdot \mathrm{min}^{-1}$ was applied at constant temperature $\left(+20 \pm 0.1{ }^{\circ} \mathrm{C}\right)$. The interaction of IBU with the BSA was studied in the concentration range 5.0-40.0 $\mu \mathrm{M}$ in PBS solution at $\mathrm{pH} 3.0$ and 7.4 under physiological conditions $(150 \mathrm{mM} \mathrm{NaCl})$. Parallel measurements were performed and the standard deviations of the sorption experiments were $\pm 4.5 \%$. In each step, $500 \mu$ BSA ( $c=$ $50 \mu \mathrm{M})$ and $500 \mu \mathrm{l}$ IBU solutions $(c=5.0 ; 10.0 ; 20.0 ; 30.0 ; 40.0 \mu \mathrm{M})$ were injected and the sorption process ( $20 \mathrm{~min}$ ) was followed by rinsing with buffer. The SPR sensorgrams were analyzed in real time by a special software package that allows determination of the resonant wavelength in both sensing channels. Based on the results of 2D SPR experiments, the rate of association and dissociation, the corresponding equilibrium constants and certain thermodynamic state functions were determined according to the following evaluation process. If the small molecules bind to the immobilised proteins, there is an association phase during which binding sites become occupied and the positive slope of SPR curve can be used to measure the rate of association $\left(k_{a}\right)$. When steady-state is achieved the RIU (refractive index unit) value corresponds to the changed final critical angle (angle modulated type) or the final wavelength of maximal plasmonic loss (wavelength modulated type). This maximum RIU value relates to the concentrations of immobilised protein and analyte molecules and so can be used to measure the binding affinity constant $\left(K_{D}=\mathrm{k}_{\mathrm{d}} / \mathrm{k}_{\mathrm{a}}\right)$. When small molecules are removed from the continuous flow there is a dissociation phase during which binding sites become unoccupied and the (negative slope) of curve can be used to measure the rate of dissociation $\left(k_{d}\right)$.

\subsection{ITC studies}


Thermometric titrations were also performed using a MicroCal VP-ITC (Isothermal Titration Calorimeter, MicroCal, USA) power compensation microcalorimeter with a cell volume of $1.4163 \mathrm{ml}$. The solutions were previously degassed by means of a vacuum degasser Thermovac (MicroCal, USA). Two parallel measurements were carried out. The enthalpy changes were recorded upon stepwise additions of BSA into the reaction cell containing ibuprofen from a $300 \mu \mathrm{L}$ syringe. Aliquots of $10 \mathrm{ml}$ were injected at periodic time intervals (10 s per injection, 5 min between injections). Blank experiments were performed in order to make corrections for the enthalpy changes corresponding to the dilution of titrant. The enthalpograms (calorimeter power signal, $P(t)=d Q / d t$ vs. $t$ ) were evaluated with Origin® 7 software supplied by MicroCal. The area below each calorimeter peak $i$ yielded a single point in S-shaped reaction enthalpy curve [21]:

$$
\Delta H_{i}=\int P_{i}(t) d t
$$

Analysis of the S-shaped curves provided the stoichiometry $(n)$ of the reaction, the binding constant $(K)$, and the standard enthalpy of binding $(\Delta H)$ according to the followings:

For a ligand $X$ binding to a single set of $n$ identical sites on a macromolecule $M$ :

$$
\begin{aligned}
& M+X=M X \\
& M X+X=M X_{2} \\
& M X_{n-1}+X=M X_{n}
\end{aligned}
$$

The binding constant $(K)$ is:

$$
\begin{gathered}
K=\frac{[\text { filled sites }]}{[\text { empty sites }][X]}=\frac{\theta}{(1-\theta)[X]} \\
X_{t}=[X]+n \theta M_{t}
\end{gathered}
$$

where $\Theta$ is the fraction of sites occupied by ligand $X, X_{t}$ and $[X]$ are bulk and free concentration of ligand, $n$ is the number of sites. The total heat content $(Q)$ of the solution contained at fractional saturation $\Theta$ is:

$$
Q=n \theta M_{t} \Delta H V_{0}
$$

where $\Delta H$ is the molar heat of ligand binding and $M_{t}$ is the bulk concentration of macromolecule in $V_{0}$ active cell volume. The one set of sites model was applied for the curve 
fitting after removing the first titration points and substracting the reference water curve. The Gibbs free energy and the entropy term of the reaction was calculated via the well-known basic thermodynamic equations $\left(\Delta \mathrm{G}^{\circ}=-\mathrm{RT} \ln \mathrm{K}\right.$ and $\left.\Delta \mathrm{G}^{\circ}=\Delta \mathrm{H}^{\circ}-\mathrm{T} \Delta \mathrm{S}^{\circ}\right)$.

\subsection{Release of IBU from BSA-IBU NPS}

The obtained BSA-IBU composites were dispersed in PBS solution. $1.5 \mathrm{ml}$ suspension was filled to the vertical diffusion cell (Franz cell; HANSON CO.) above a cellulose membrane (Sigma-Aldrich). Owing to the $\mathrm{pH}$-changes, the IBU starts to diffuse through the membrane to the pure PBS buffer. The concentration of the IBU was recorded by UV-1800 spectrophotometer at $264 \mathrm{~nm}$. The absorbance spectra were taken every $10 \mathrm{~min}$ in the first hour than once an hour to $500 \mathrm{~min}$. Every measurement was repeated twice.

\section{Results and discussion}

\subsection{The pH-dependent structure of BSA determined by DLS, SAXS and SPR experiments}

It is well-known that the $\mathrm{pH}$ has a prominent role in the change of protein structure and the substrate binding as well [22]. The knowledge of the exact structure of the protein at different $\mathrm{pH}$ is necessary to design protein-based NPs for encapsulation of drug molecules. Since the BSA-IBU NPs were fabricated at $\mathrm{pH} 3.0$ and the spontaneous release of IBU from NPs was measured at $\mathrm{pH} 7.4$, the size and the structure of BSA at the previously mentioned $\mathrm{pH}$ values were studied by DLS, SAXS and the two-dimensional SPR experiments. Figure 1 represents the Kratky (a), Guinier (b) plots and pair distance distribution functions (c) of BSA colloid solutions at different $\mathrm{pH}$. The Kratky plot $\left(I h^{2} v s\right.$. $h$, where $I$ is the scattering intensity and $h$ is the scattering vector) representation provides information about the secondary structure of the protein, it is informative about both the globularity and the flexibility of the protein. In the case of folded globular protein, the Kratky plot will show a peak at low $q$ values. If the curve does not converge to the $q$-axis at high $q$ that indicates that the protein has a definite flexibility. Both the peak and the divergence from the $q$-axis refers dominantly the presence of a flexible folded state of the protein (Fig. 1a, pH 7.4, $c_{B S A}=20.0 \mathrm{w} / \mathrm{v} \%$ ). Decrease in the $\mathrm{pH}$ causes the change of the shape of the Kratky plot (decrease of the peak, Fig. 1a, $\mathrm{pH}$ 3.0). This shape preferably indicates the formation of an unfolded state of the BSA. The Guinier plot $\left(\ln I v s . h^{2}\right)$ (Fig. 1.b) and the pair distance distribution function (PDDF) (Fig. 1.c) are suitable to determine the size and morphology of the molecules. The radius of gyration $\left(R_{g}\right)$ of the molecule can be calculated by linear fitting of the initial range 
$(h R g<1.3)$ of the scattering curve in $\ln I v s . h^{2}$ representation (Fig. 1b). As it can be seen the smaller radius of gyration $\left(R_{g}=2.02 \mathrm{~nm}\right)$ is determined for the BSA solution at $\mathrm{pH} 7.4$ while the larger $R_{g}$ value $\left(R_{g}=2.64 \mathrm{~nm}\right)$ belongs to the $20.0 \mathrm{w} / \mathrm{v} \% \mathrm{BSA}$ solution at $\mathrm{pH} 3.0$. These data are in good agreement with the results of both Kratky and the PDDA representations as well. On the whole, the detailed SAXS results strongly support that the BSA has an unfolded (larger extension) structure at acidic pH (Fig. 1c, $\mathrm{pH} 3.0$, the largest extension is $9.0 \mathrm{~nm}$ ), while the formation of a flexible folded structure (smaller extension) (Fig. 1c, pH 7.4, the largest extension is only $6.3 \mathrm{~nm}$ ) is confirmed at neutral $\mathrm{pH}$. The DLS measurements also confirm the above mentioned $\mathrm{pH}$-dependent structural changes of the protein. Namely, the measured average hydrodynamic diameter of BSA is $d=3.8 \pm 0.3 \mathrm{~nm}$ (polydispersity index, $\mathrm{PDI}=0.344)$ at $\mathrm{pH} 3.0$, while $d=8.2 \pm 0.2 \mathrm{~nm}(\mathrm{PDI}=0.221)$ was obtained at $\mathrm{pH}$ 7.4. Besides the classic three-dimensional techniques, two-dimensional SPR experiments were also performed to get deeper information on the size and structure (orientation) of BSA at different $\mathrm{pH}$. The studied protein was immobilized onto the gold surface from aqueous solution $(c=$ $0.05 \mathrm{mM}$ ) at $25{ }^{\circ} \mathrm{C}$. The registered SPR sensorgrams are presented in Figure 2. As it can be seen that $61.5 \%$ and $70.0 \%$ of adsorbed amount remains irreversibly bound at gold surface after rinsing procedure at $\mathrm{pH} 3.0$ and 7.4, respectively. Most probably the protein is bonded onto the gold surface via cysteine residues resulting the formation of Au-S covalent bond. The binding of BSA on gold surface caused $\Delta \lambda_{p H} 3.0=2.8 \mathrm{~nm}$ and $\Delta \lambda_{p H} 7.4=4.1 \mathrm{~nm}$ plasmon shifts which correspond to the $m_{p H 3.0}^{s}=56.5 \mathrm{ng} \mathrm{cm}^{-2}$ and $m_{p H 7.4}^{s}=86.0 \mathrm{ng} \mathrm{cm}^{-2}$ adsorbed amount of BSA. According to the calculation procedure published previously [15,23-25] the cross sectional area $\left(a_{m} / \mathrm{nm}^{2}\right)$ of the BSA at acidic and neutral $\mathrm{pH}$ values was determined. It was found that the $\mathrm{a}_{\mathrm{m}}$ for BSA is $195.4 \mathrm{~nm}^{2} /$ protein $\left(\mathrm{pH} 3.0\right.$ ) and $128.4 \mathrm{~nm}^{2} /$ protein $(\mathrm{pH} 7.4$ ) on gold surface under the applied conditions. Taking into account that the protein covalently binds onto the gold sensor surface the $\mathrm{pH}$-dependent changes in the secondary structure of BSA were proven in 2D systems as well indicating the larger cross sectional area of BSA is obtained at $\mathrm{pH}$ 3.0. On the whole, the size of the BSA at acidic and at neutral $\mathrm{pH}$ determined by SPR are in good agreement with the DLS and SAXS measurements.

\subsection{Characterization of the size of the BSA-IBU NPs by HRTEM, DLS and SAXS results}

Based on the results of SPR experiments, BSA-IBU composite particles were successfully prepared at different BSA:IBU molar ratios. The Fig. 3.a shows the pair distance distribution functions for pure BSA and BSA:IBU NPs at 1:1 and 1:10 ratios obtained by SAXS. As it can be seen, the largest extension of the scattering objects continually increases 
in the admixture of IBU to BSA solution. (pure BSA: $d_{S A X S}=9.0 \mathrm{~nm}$; BSA:IBU (1:1) NPs: $d_{S A X S}=10.0 \mathrm{~nm}$; BSA:IBU (1:10) NPs: $\left.d_{S A X S}=10.5 \mathrm{~nm}\right)$. The sizes of NPs obtained by SAXS are in good agreement with the HRTEM images and also the parallel DLS experiments. The Fig. 3.c represents an image of BSA:IBU (1:10) NPs, the calculated average diameter is $d_{\text {HRTEM }}=12.9 \pm 0.5 \mathrm{~nm}$, while the parallel DLS curves (Fig. 3.b) indicate the formation of NPs with $d_{D L S}=11.8 \pm 1.9 \mathrm{~nm}$ (average hydrodynamic diameter).

\subsection{Quantification of the interaction between BSA and IBU by SPR experiments}

The interaction of IBU with BSA were investigated by SPR to provide quantitative data of the protein-biomolecule bindings. In order to determine the binding capacity of IBU on BSA-covered gold surface the sorption/binding of IBU on protein-functionalized biosensor chip was investigated at $+25 \pm 0.1{ }^{\circ} \mathrm{C}$ in the concentration range of $5-40 \mu \mathrm{M}$. The registered sensorgrams in Fig. 4. indicate that an increase in the concentration of the IBU solution from $5 \mu \mathrm{M}$ to $40 \mu \mathrm{M}$ results in a larger sorbed amount on the functionalized surface at both studied $\mathrm{pH}\left(m_{p H 3}^{s}=\max .75-80 \mathrm{ng} \mathrm{cm}{ }^{-2}, m_{p H}^{s} 7.4=\max .12-15 \mathrm{ng} \mathrm{cm}^{-2}\right)$. Moreover, the experiments clearly support that measurable high amount of IBU is bonded on BSA-covered gold surface at acidic $\mathrm{pH}$ than that at $\mathrm{pH}$ 7.4. Namely, $m=1239 \mathrm{mg}$ IBU is bonded to BSA (referring to $1.0 \mathrm{~g}$ serum albumin protein) at acidic $\mathrm{pH}$ while the bonded amount of IBU on BSA-covered gold surface is only $0.174 \mathrm{mg}$ at $\mathrm{pH}$ 7.4. Most probably the availability of hydrophobic binding sites of BSA is more favoured for hydrophobic IBU molecules at acidic $\mathrm{pH}$ because of the unfolded structure. Because the water solubility of IBU is relatively less at pH 3.0 and above the concentration of $10 \mu \mathrm{M}$ the aqueous solution is opalescent causing suddenly high changes in the refractive index which is highlighted with grey colour in Fig. 4. Based on this observation, only the effectively bound amount of IBU (signed with arrows) is used for the calculations. The sensorgrams also confirm that the interaction between the IBU molecules and the protein is fully reversible at $\mathrm{pH} 7.4$ (Fig. 4. inset) because the adsorbed mass of IBU fell to nearly zero on rinsing. The confirmation of this reversible interaction is crucial in order to design potential nanocarrier composite system(s) for (controlled) drug release.

\subsection{Thermodynamic characterization of BSA-IBU system by ITC}

A representative calorimetric titration curves of IBU with BSA aqueous solution at $\mathrm{pH} 3.0$ and 7.4 were reported in Fig. 5. It was found that the interaction between IBU and BSA in aqueous solution both at $\mathrm{pH} 3.0$ and 7.4 was exothermic process at $25^{\circ} \mathrm{C}$ with $\Delta H^{\circ}=-22.85 \pm$ 
$0.57 \mathrm{~kJ} \mathrm{~mol}^{-1}$ and $-19.57 \pm 0.82 \mathrm{~kJ} \mathrm{~mol}^{-1}$, respectively. As expected, the value of $n$ and $K$ indicated higher affinity at acidic $\mathrm{pH}$ with significantly more IBU molecules (values summarized in Table 1) bound to BSA and the binding constant decreased from $3620 \pm 89 \mathrm{M}^{-}$

${ }^{1}$ to $1110 \pm 242 \mathrm{M}^{-1}$ with increasing $\mathrm{pH}$. The relative magnitudes of the enthalpy and entropy changes determine the resultant change in the Gibbs energy, which is thermodynamically favoured, must be negative for a spontaneous process. The values of binding constants, stoichiometry and the thermodynamic state functions are given in Table 1. The major driving force or the interaction originates from the van der Waals interaction between the BSA and the IBU molecules and the hydrophobic effect, the release of high energy water molecules from the BSA cavity. The van der Waals interactions between the host and the guest species are exothermic, accompanied by some entropy loss. In aqueous solution, apolar molecules are surrounded by water molecules with a higher hydrogen-bond density relative to the hydrogenbond density of pure water. Upon interaction, molecules leave the solution and break this hydration structure; the collapse of this "iceberg" structure is an endothermic process accompanied by entropy production.

\subsection{Kinetic studies in $2 D$ and in $3 D$ systems}

Since the SPR signal responds directly to the amount of bound ligand in real time, it provides a very powerful technique to study protein-ligand or any other biomolecular interaction thermodynamics and kinetics. The protein-based nanocomposite containing IBU was prepared at $\mathrm{pH} \mathrm{3.0,} \mathrm{but} \mathrm{the} \mathrm{release} \mathrm{of} \mathrm{the} \mathrm{drug} \mathrm{was} \mathrm{measured} \mathrm{at} \mathrm{pH} 7.4$ under physiological conditions. Based on it, the SPR sensorgrams registered at $\mathrm{pH} 7.4$ was used for detailed kinetic calculations. Assuming the $\mathrm{A}+\mathrm{B} \leftrightarrow \mathrm{AB}$ type reversible process is first-order for each reactants in the association phase and the dissociation is also first-order thus the following overall rate low can be given:

$$
\frac{d[A B]}{d t}=k_{a}[A][B]-k_{d}[A B]
$$

where $[\mathrm{B}]$ is the concentration of immobilized protein and $[\mathrm{A}]$ is the concentration of the aqueous IBU solution, while the $[\mathrm{AB}]$ is the surface concentration of the BSA-IBU complex. According to the research work of O'Shannessy et al. [26] integrated rate law in the association process shows first order growth for the complex:

$$
[A B]=[B]_{0}\left(1-e^{-k_{o b s} t}\right)
$$

where the observed rate constant is: 


$$
k_{o b s}=k_{a}[A]_{0}+k_{d}
$$

In the dissociation phase, when only buffer is flowing over the BSA-covered gold surface, $\left([A]_{0} \approx 0\right)$ the concentration of BSA-IBU complex decreases exponentially with a dissociation rate constant:

$$
[A B]=[A B]_{0} e^{-k_{d} t}
$$

A reasonable assumption is that the $\Delta \lambda$ reading is proportional to the concentration of bound complex, $\Delta \lambda=\alpha[A B]$. Since the maximum concentration of the complex is $[A B]_{\max }=[B]_{0}$, we can determine the maximum $\Delta \lambda$ value, $\Delta \lambda_{\max }=\alpha[\mathrm{AB}]=\alpha[\mathrm{B}]_{0}$. Multiplying the Eq. (9) and (11) by the proportional factor $(\alpha)$ the following equations for association and dissociation reactions can be given:

$$
\begin{aligned}
& \Delta \lambda=\Delta \lambda_{\max }\left(1-e^{-k_{o b s} t}\right) \\
& \Delta \lambda=\Delta \lambda_{\max } e^{-k_{d} t}
\end{aligned}
$$

Based on Eq. (12-13) and the registered sensorgrams, the rate constants were determined by using nonlinear regression process. The Fig. 6.a shows the measured (black) and the fitted (grey) sensorgrams. Rate constant of association and dissociation process can be determined from the slope and the intercept of the observed rate constant $v s$. concentration of the aqueous IBU solution plot (not presented here) according to Eq. (10). Linear regression analysis of the previously mentioned $\mathrm{k}_{\mathrm{obs}} v s . \mathrm{c}_{\mathrm{BBU}}$ plot results the following parameters: $k_{a}=128 \pm 9 \mathrm{M}^{-1} \mathrm{~s}^{-1}, k_{d}$ $=0.02 \pm 0.04 \mathrm{~s}^{-1}, K_{A}=5965 \pm 420 \mathrm{M}^{-1}$ and $\Delta G^{\circ}=-21.5 \pm 0.2 \mathrm{kJmol}^{-1}$. As it can be seen, if we use linear regression the intercept $\left(k_{d}\right)$ have high standard deviation. To avoid this uncertainty the rate constant of dissociation was extracted from exponential curve fitting to Eq. (13) (Fig. 6.a). In this case the dissociation rate constant obtained by the nonlinear regression is $k_{d}=$ $6.1 \times 10^{-3} \pm 3.7 \times 10^{-4} \mathrm{~s}^{-1}$. Despite of the above mentioned uncertainty of $\mathrm{k}_{\mathrm{d}}$, the calculated value for the Gibbs free energy $\left(\Delta G^{\circ}\right)$ obtained by linear regression analysis shows good agreement with the ITC experiments (Table 1). Namely, the Gibbs free energy of BSA-IBU complex formation at $\mathrm{pH} 7.4$ is $\Delta \mathrm{G}^{\circ}=-21.5 \pm 0.2 \mathrm{kJmol}^{-1}$ based on the observed rate constant using kinetic analysis while $\Delta \mathrm{G}^{\circ}=-17.38 \pm 0.54 \mathrm{kJmol}^{-1}$ is determined according to ITC result.1

1 The Gibbs free energy of BSA-IBU complex formation originates from the difference between the Gibbs free energy of the unbounded state (before binding) and the saturated state (after binding). 
The release of the IBU from the composite NPs was measured in aqueous solution by using vertical diffusion cell at $25{ }^{\circ} \mathrm{C}$. The registered release profile was shown in Fig. 6.b. As it can be seen that the release process starts slower in the case of the $3.9 \mathrm{w} / \mathrm{v} \%$ sample [19] but after 500 min the dissolved amount of the IBU became equal. Various kinetic models (presented in Table 2) were applied to describe the release mechanism of the IBU from NPs. The correlation coefficient $\left(\mathrm{R}^{2}\right)$ and the release rate $\left(k_{d}\right)$ values at $25{ }^{\circ} \mathrm{C}$ are summarized in Table 2. The $\mathrm{R}^{2}$ values indicate the accuracy of the applied kinetic model. Although the release profiles run same way, the release mechanism is definitely different. If we use BSA in lower concentration - the protein-drug molar ratio is same in both cases - the release of the drug molecule is independent on its concentration. If the BSA concentration is higher the release mechanism follows very well the first-order rate model, which means that the drug release rate depends on its concentration. The results show that the release mechanism of the drug can be influenced by the BSA concentration, not only by forming shells around the protein core.

\section{Conclusion}

The design of novel nanocarrier composite systems plays an important role in different pharmaceutical developments. In order to produce potent nanosized composite particles including drug molecules the holistic characterization of the interactions between the carrier material(s) (e.g. proteins) and the drug agent(s) are crucial. Besides quantification of the interaction, the quantitative study of the binding thermodynamics and the knowledge of the kinetics of the drug release process are necessary. However numerous research group focus their studies on the characterization of biomolecular interactions by SPR or ITC measurements, we successfully used the two-dimensional SPR technique for kinetic and thermodynamic evaluations draw a parallel between the results of individual measuring techniques and theories using in $3 \mathrm{D}$ systems. We confirmed that the important physicalchemical parameters of a protein-drug molecule interactions obtained by SPR are in good agreement with the results of the classic three-dimensional SAXS, DLS, ITC and release studies in solution. Based on the experimental results (quantitative, kinetic and thermodynamic data) of this sensor technique our work may contribute to the development of novel nanosized drug-carrier NPs.

\section{Acknowledgement}


The authors are very thankful for the financial support from the Hungarian Scientific Research Fund (OTKA) K 116323. 


\section{References}

[1] L. Brannon-Peppas, J. O. Blanchette, Nanoparticle and targeted systems for cancer therapy, Advanced Drug Delivery Reviews, 64 (2012) 206-212.

[2] A. Kumari, S. Kumar Yadav, S. C. Yadav, Biodegradable polymeric nanoparticles based drug delivery systems, Coll. Surf. B. 75 (2010) 1-18.

[3] C. Shi, D. Guo, K. Xiao, X. Wang, L. Wang, J. Luo, A drug-specific nanocarrier design for efficient anticancer therapy, Nature Communications, 6 (2015) 7449.

[4] G. Liu, M. Swierczewska, S. Lee, X. Chen, Functional nanoparticles for molecular imaging guided gene delivery, Nano Today 5 (2010) 524-539.

[5] J. Hannah Lee, Y. Yeo, Controlled drug release from pharmaceutical nanocarriers, Chemical Engineering Science 125 (2015) 75-84.

[6] N. Sanvicens, M. P. Marco, Multifunctional nanoparticles - properties and prospects for their use in human medicine, Trends in Biotechnology 26 (2008) 425-433.

[7] C. Deng, Y. Jiang, R. Cheng, F. Meng, Z. Zhong, Biodegradable polymeric micelles for targeted and controlled anticancer drug delivery: Promises, progress and prospects, Nano Today 7 (2012) 467-480.

[8] P.-L. Lam, S. H.-L. Kok, R. Gambari, T.-W. Kok, H.-Y. Leung, K.-L. Choi, C.-S. Wong, D. K.-P. Hau, W.-Y. Wong, K. H. Lam, Z.-X. Bian, K. K.-H. Lee and C.-H. Chui, Evaluation of berberine/bovine serum albumin nanoparticles for liver fibrosis therapy, Green Chem. 17 (2015) 1640-1646.

[9] J. Siepmann, F. Siepmann, Mathematical modeling of drug delivery, International Journal of Pharmaceutics 364 (2008) 328-343.

[10] L.A.A. de Jong, D.R.A. Uges, J.P. Franke, R. Bischoff, Receptor-ligand binding assays: Technologies and applications, J Chromatography B, 829 (2005) 1-25.

[11] R.J Ward, G. Milligan, Structural and biophysical characterisation of G protein-coupled receptor ligand binding using resonance energy transfer and fluorescent labelling techniques, Biochim Biophys Acta. 1838 (2014) 3-14.

[12] T. Heyduk, Measuring protein conformational changes by FRET/LRET, Curr. Opin. Biotechnol 13 (2002) 292-296.

[13] H. Sípová, J. Homola, Surface plasmon resonance sensing of nucleic acids: a review, Anal. Chim. Acta, 773 (2013) 9-23.

[14] W.A. Murray, W.L. Barnes, Plasmonic Materials, Adv. Materials, 19 (2007) 3771-3782.

[15] D. Sebők, E. Csapó, T. Preocanin, G. Bohus, N. Kallay, I. Dékány, Adsorption of ibuprofen and dopamine on functionalized gold using surface plasmon resonance spectroscopy at solid-liquid interface, Croat. Chem. Acta 86 (2013) 287-295.

[16] R.B M Schasfoort, A. J Tudos, Handbook of Surface Plasmon Resonance, Cambridge, UK, 2008. 
[17] D.G Myszka, Kinetic analysis of macromolecular interactions using surface plasmon resonance biosensors, Current Opinion in Biotechnology, 8 (1997) 50-57.

[18] C. Ràfols, S. Zarza, E. Bosch: Molecular interactions between some non-steroidal antiinflammatory drugs (NSAID's) and bovine (BSA) or human (HAS) serum albumin estimated by means of isothermal titration (ITC) calorimetry and frontal analysis capillary electrophoresis (FA/CE). Talanta 130 (2014) 241-250.

[19] N. Varga, M. Benkő, D. Sebők, I. Dékány, BSA/polyelectrolyte core-shell nanoparticles for controlled release of encapsulated ibuprofen, Coll. Surf. B, 123 (2014) 616-622.

[20] M. Benkő, N. Varga, D. Sebők, G. Bohus, Á. Juhász, I. Dékány, Bovine serum albumin-sodium alkyl sulfates bioconjugates as drug delivery systems, Coll. Surf. B, 130 (2015) 126-132.

[21] M. Benkö, Z. Király, Thermodynamics of inclusion complex formation of b-cyclodextrin with a variety of surfactants differing in the nature of headgroup. J. Chem. Thermodynamics 54 (2012) 211-216.

[22] R. Buratto, D. Mammoli, E. Chiarparin, G. Williams, G. Bodenhausen, Exploring weak ligand-protein interactions by long-lived NMR states: improved contrast in fragment-based drug screening, Angew. Chem. Int. Ed. Engl. 53 (2014) 11376-80.

[23] E. Csapó, Z. Majláth, Á. Juhász, B. Roósz, A. Hetényi, J. Tajti, G.K. Tóth, L. Vécsei, I. Dékány, Determination of binding capability and adsorption enthalpy between Human Glutamate Receptor (GluR1) peptide fragments and kynurenic acid by surface plasmon resonance experiments, Coll. Surf. B, 123 (2014) 924-929.

[24] E. Csapó, F. Bogár, Á. Juhász, D. Sebők, J. Szolomájer, Zs. Majláth, G.K. Tóth, L. Vécsei, I. Dékány, Determination of binding capability and adsorption enthalpy between Human Glutamate Receptor (GluR1) peptide fragments and kynurenic acid by surface plasmon resonance experiments: Part 2, Interaction of GluR1270-300 with KYNA, Coll. Surf. B, 133 (2015) 66-72.

[25] N. Varga, E. Csapó, Z. Majláth, I. Ilisz, I.A. Krizbai, I. Wilhelm, L. Knapp, J. Toldi, L. Vécsei, I. Dékány, Targeting of the kynurenic acid across the blood-brain barrier by core-shell nanoparticles, Eur. J. Pharm. Sci., 86 (2016) 67-74.

[26] D.J. O’Shannessy, M. Brigham-Burke, K.K. Soneson, P. Hensley and I. Brooks, Determination of rate and equilibrium binding constants for macromolecular interactions using surface plasmon resonance: use of nonlinear least squares analysis methods, Anal. Biochem, 212 (1993) 457-468. 


\section{Figure captions}

Figure 1. Kratky (a), Guinier (b) plots and pair distance distribution function (c) of aqueous BSA solutions at $\mathrm{pH} 3.0$ and 7.4. $c_{B S A}=20 \mathrm{w} / \mathrm{v} \%$.

Figure 2. Representative SPR sensorgrams of the binding of BSA onto gold surface at different $\mathrm{pH}\left(c_{B S A}=50 \mu \mathrm{M}, I=150 \mathrm{mM}(\mathrm{NaCl})\right.$ in PBS, $T=25^{\circ} \mathrm{C}$, flow rate of $\left.25 \mu \mathrm{L} \mathrm{min}{ }^{-1}\right)$.

Figure 3. PDDA representations of BSA, BSA:IBU 1:1 and 1:10 NPs (a), the parallel DLS distribution functions (b) and a representative HRTEM image of BSA:IBU 1:10 NPs (c) at pH 3.0 .

Figure 4. Representative SPR sensorgrams of the binding of IBU onto the BSAfunctionalized gold surface at $\mathrm{pH} 3.0$ and $\mathrm{pH} 7.4$ (inset) $(I=150 \mathrm{mM}(\mathrm{NaCl})$ in $\mathrm{PBS}, T=25$ ${ }^{\circ} \mathrm{C}$, flow rate of $25 \mu \mathrm{L} \mathrm{min}^{-1}$ ).

Figure 5. Representative calorimetric titration curves of IBU with BSA solution at $\mathrm{pH} 3.0$ (a) and $7.4(\mathbf{b})$ at $25^{\circ} \mathrm{C}$.

Figure 6. The measured (black) and the fitted (grey) sensorgrams to evaluate the kinetics of BSA-IBU interaction at pH 7.4 under physiological conditions (a) and the release profile of the IBU from the NPs at $25^{\circ} \mathrm{C}$ at $\mathrm{pH} 7.4$ (b).

Table 1. Thermodynamic state functions, stoichiometry and binding constants determined from ITC and SPR measurements $\left(T=25^{\circ} \mathrm{C}\right)$.

Table 2. The rate of dissociation $\left(k_{d}\right)$ for the IBU at $25^{\circ} \mathrm{C}$ by SPR (2D) and by release studies in solution (3D). 
Table 1.

\begin{tabular}{|c|c|c|c|c|c|c|}
\hline $\begin{array}{c}\text { BSA-IBU } \\
\text { interaction }\end{array}$ & $\begin{array}{c}\text { bonded } \\
\text { amount of } \\
\text { IBU }\end{array}$ & $\begin{array}{c}\begin{array}{c}\mathbf{K}_{\mathrm{A}} \\
\left(\mathrm{dm}^{3} \mathrm{~mol}^{-1}\right)\end{array} \\
\end{array}$ & $\mathbf{n}$ & $\begin{array}{c}\Delta \mathbf{H}^{\circ} \\
\left(\mathbf{k J} \mathbf{m o l}^{-1}\right)\end{array}$ & $\begin{array}{c}\Delta \mathbf{G}^{\circ} \\
\left(\mathbf{k J} \mathbf{m o l}^{-1}\right)\end{array}$ & $\begin{array}{c}\mathbf{T} \Delta \mathrm{S}^{\circ} \\
\left(\mathbf{k J} \mathbf{m o l}^{-1}\right)\end{array}$ \\
\hline \multirow[t]{2}{*}{ ITC $\mathrm{pH} 3.0$} & $45.9 \mathrm{mg}^{\#}$ & $3.62 \times 10^{3} \pm 89$ & $22.1 \pm 0.1$ & $-22.85 \pm 0.57$ & $-20.31 \pm 0.06$ & $-2.54 \pm 0.57$ \\
\hline & $40.5 \mathrm{mg}^{\#}$ & $1.11 \times 10^{3} \pm 242$ & $10.3 \pm 0.5$ & $-19.57 \pm 0.82$ & $-17.38 \pm 0.54$ & $-2.19 \pm 0.98$ \\
\hline SPR pH 7.4 & $174 \mathrm{mg}^{*}$ & $5.97 \times 10^{3} \pm 420$ & n.i. & n.i. & $-21.5 \pm 0.2$ & n.i. \\
\hline
\end{tabular}


Table 2.

\begin{tabular}{|c|c|c|c|c|}
\hline IBU release & kinetic models & & 3.9 \% BSA-IBU & $20.0 \%$ BSA-IBU \\
\hline \multirow{6}{*}{$\begin{array}{l}\text { Drug release kinetics } \\
\text { in solution }(3 D)\end{array}$} & \multirow{2}{*}{$\begin{array}{l}\text { zero-order }\left(\mathrm{s}^{-1}\right) \\
\text { (independent from } \\
\text { concentration) }\end{array}$} & $\mathrm{k}_{\mathrm{d}}$ & $6.48 \times 10^{-2} \pm 5.6 \times 10^{-4}$ & $1.38 \times 10^{-1} \pm 5.2 \times 10^{-3}$ \\
\hline & & $\mathrm{R}^{2}$ & 0.990 & 0.984 \\
\hline & \multirow{2}{*}{$\begin{array}{l}\text { first-order }\left(\mathrm{s}^{-1}\right) \\
\text { (dependent upon the } \\
\text { concentration) }\end{array}$} & $\mathrm{k}_{\mathrm{d}}$ & $1.50 \times 10^{-3} \pm 9.9 \times 10^{-4}$ & $2.40 \times 10^{-3} \pm 1.4 \times 10^{-4}$ \\
\hline & & $\mathrm{R}^{2}$ & 0.989 & 0.995 \\
\hline & \multirow{2}{*}{$\begin{array}{c}\text { Higuchi }\left(\mathrm{s}^{-1 / 2}\right) \\
\text { (diffusion-controlled) }\end{array}$} & $\mathrm{k}_{\mathrm{d}}$ & $6.07 \times 10^{-1} \pm 1.2 \times 10^{-1}$ & $3.65 \times 10^{0} \pm 7.8 \times 10^{-4}$ \\
\hline & & $\mathrm{R}^{2}$ & 0.964 & 0.992 \\
\hline \multirow{2}{*}{$\begin{array}{l}\text { SPR kinetic } \\
\text { experiments } \\
\quad(2 D)\end{array}$} & \multirow{2}{*}{$\begin{array}{l}\text { first-order }\left(\mathrm{s}^{-1}\right) \\
\text { (dependent upon the } \\
\text { concentration) }\end{array}$} & $\mathrm{k}_{\mathrm{d}}$ & \multirow{2}{*}{\multicolumn{2}{|c|}{$\begin{array}{c}6.09 \times 10^{-3} \pm 3.65 \times 10^{-4} \\
0.964\end{array}$}} \\
\hline & & $\mathrm{R}^{2}$ & & \\
\hline
\end{tabular}


(a)

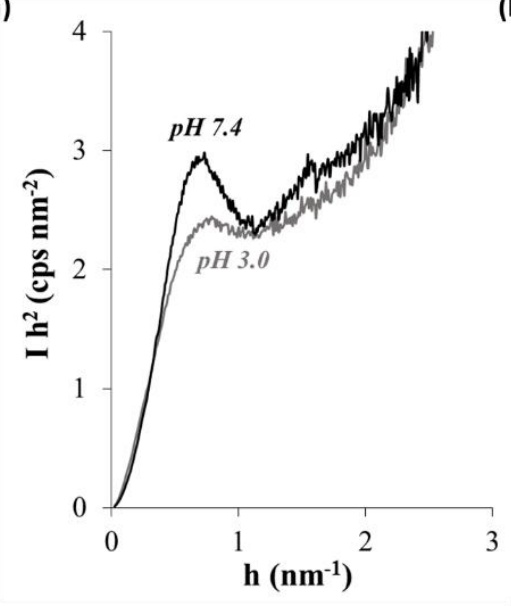

(b)

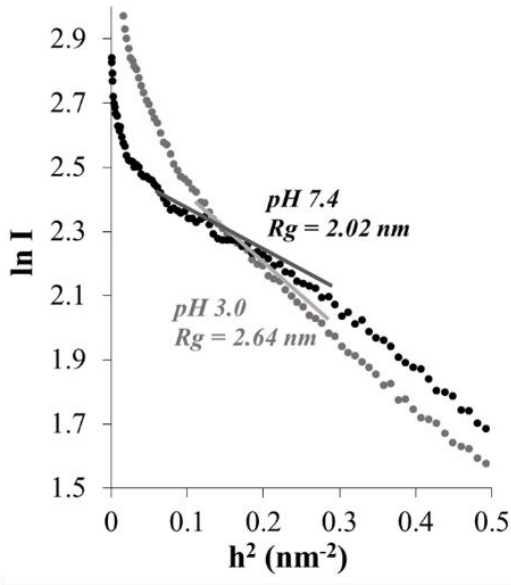

(c)

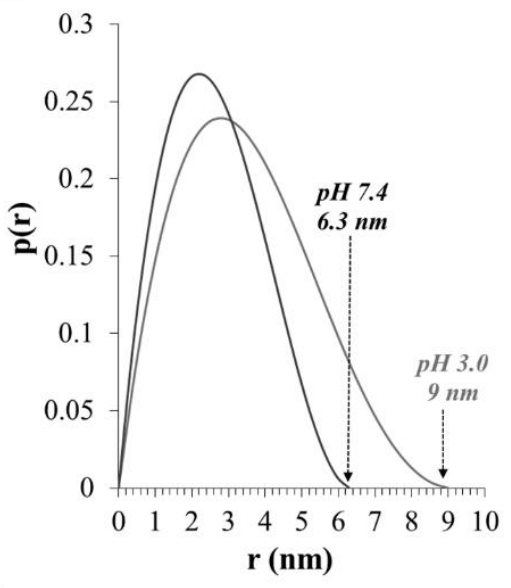

Figure 1. 


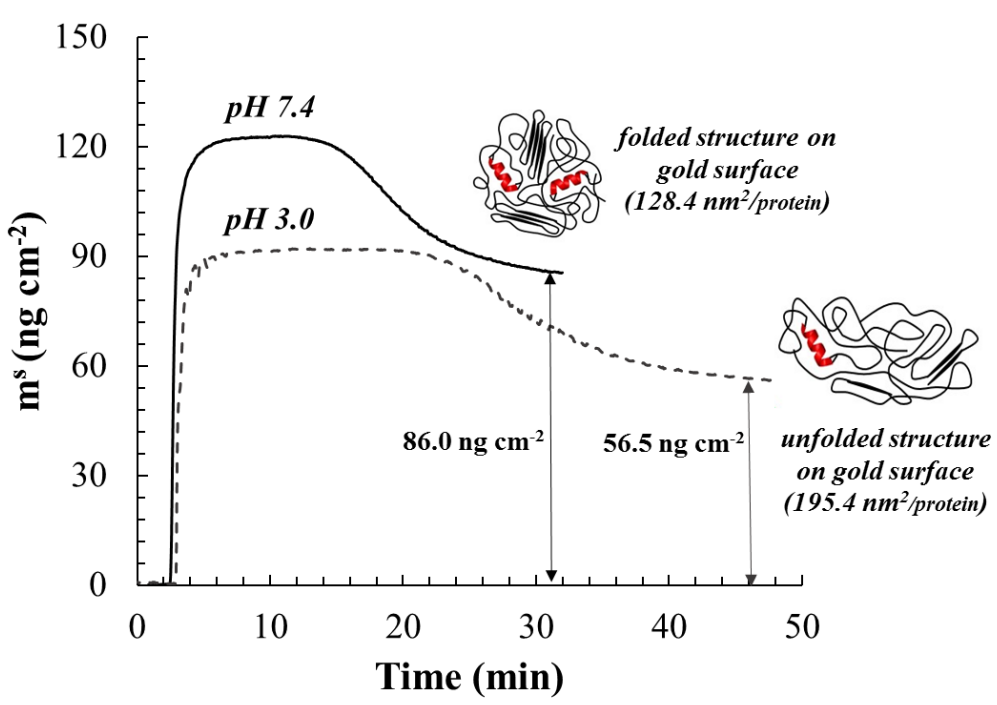

Figure 2. 
(a)

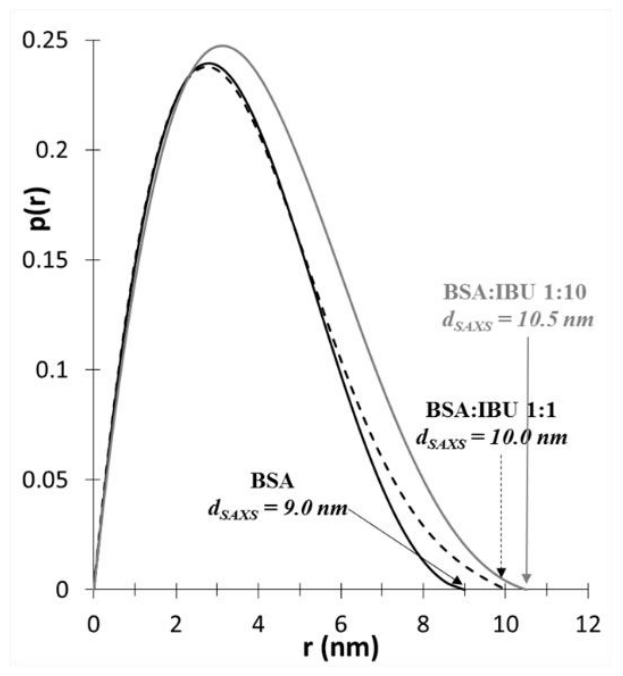

(b)

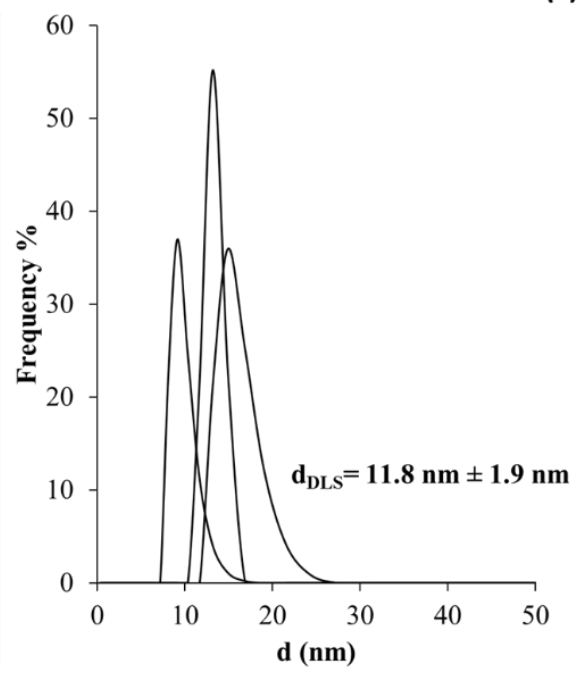

(c)

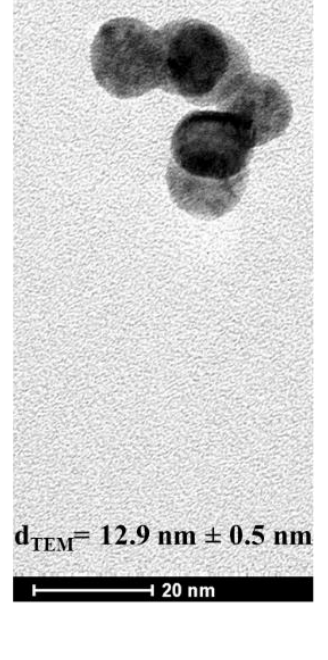

Figure 3. 


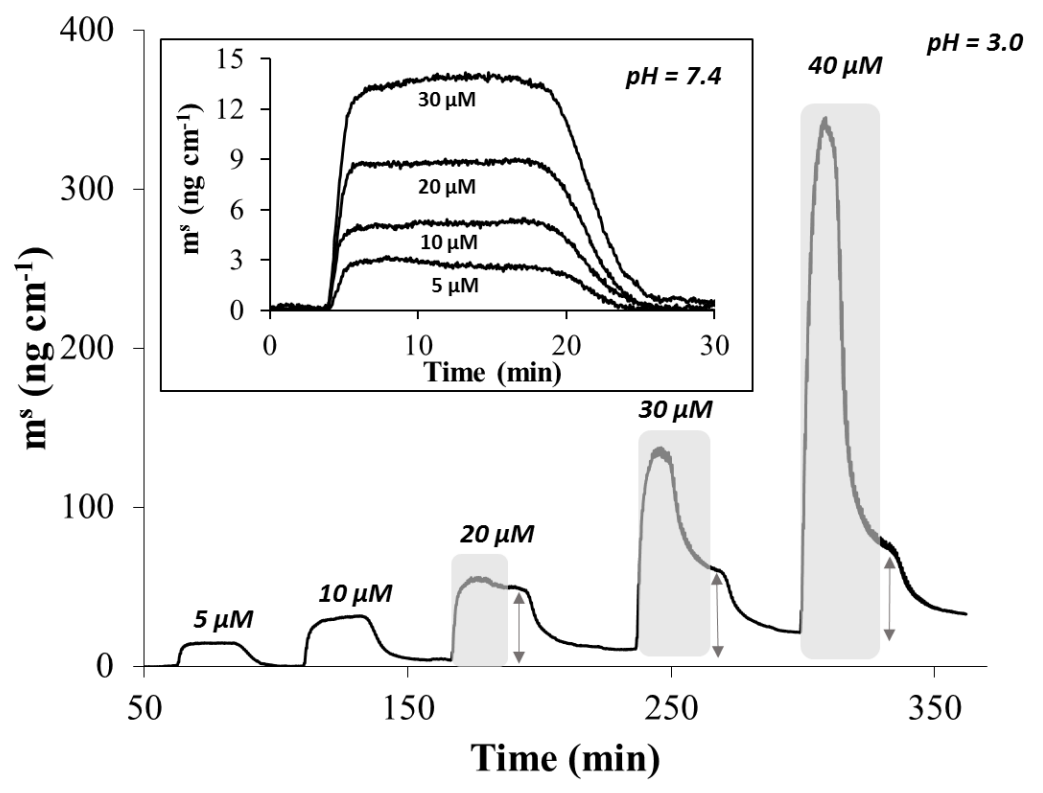

Figure 4. 

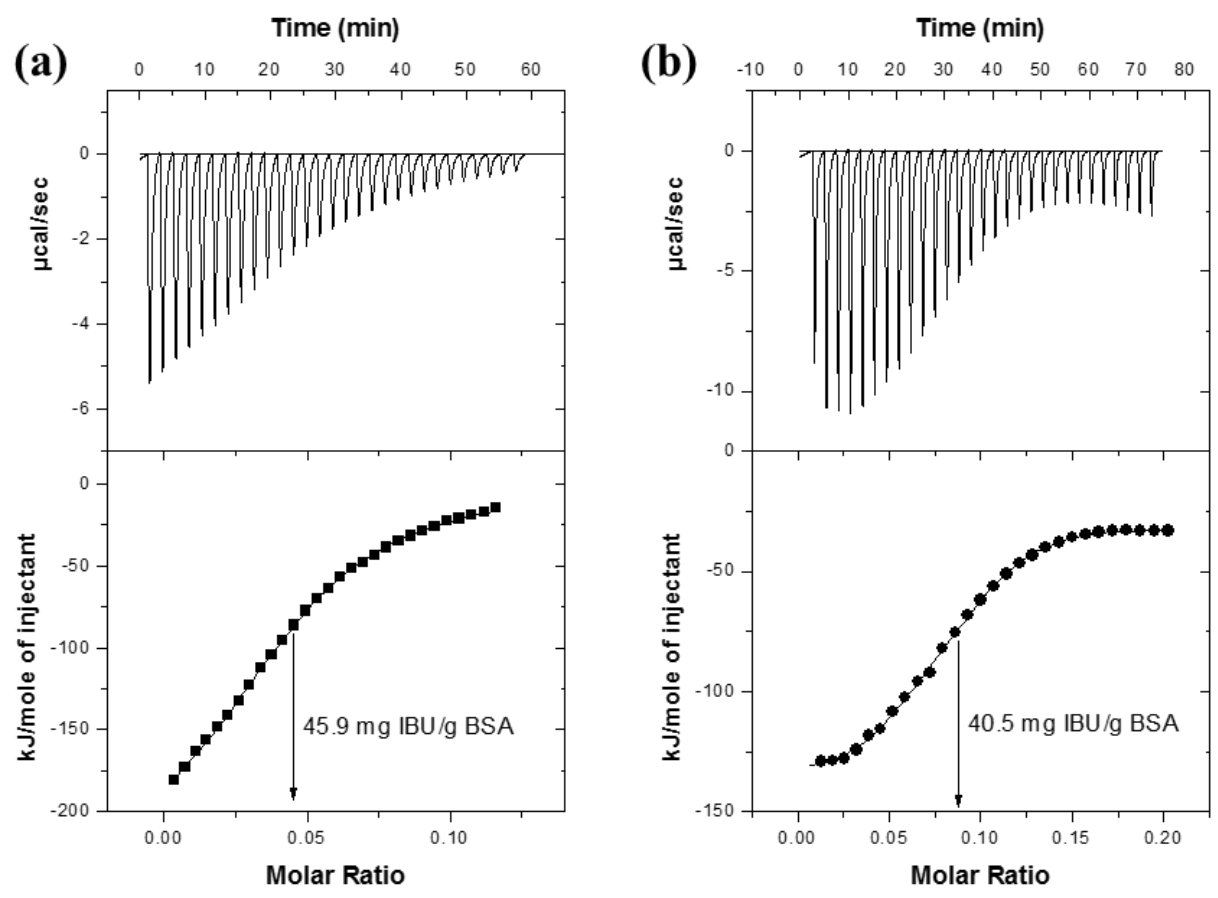

Figure 5. 
(a)

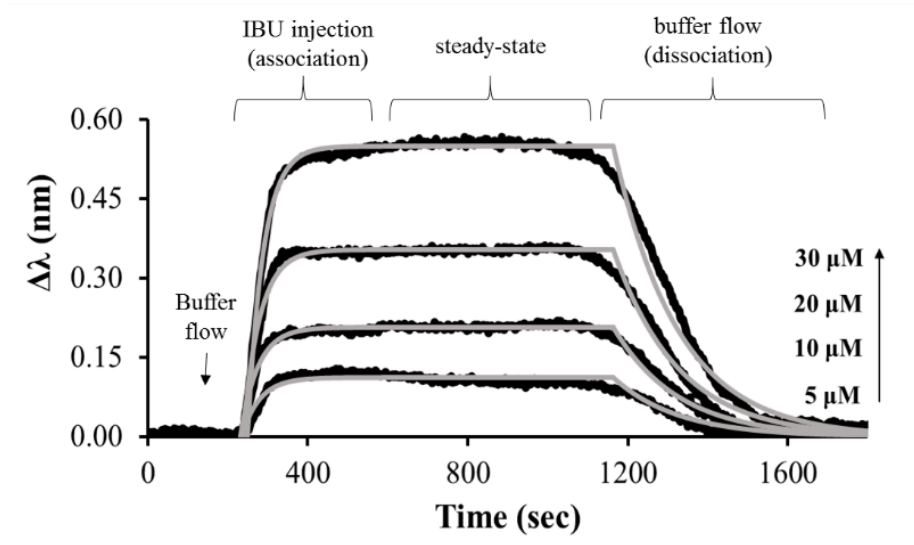

(b)

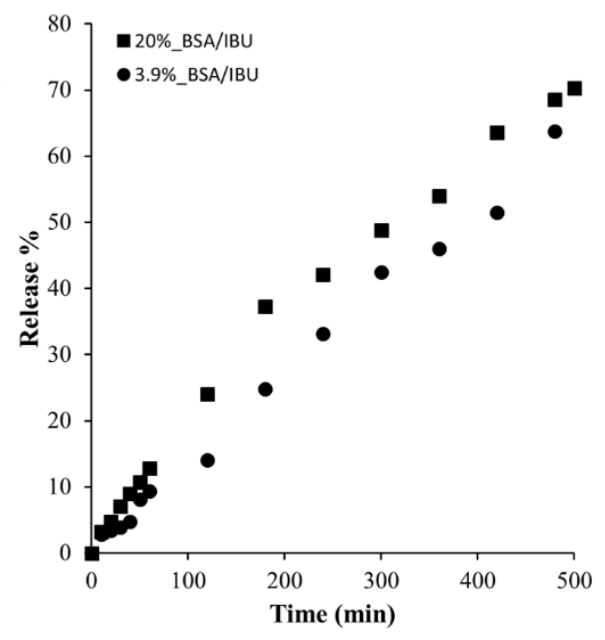

Figure 6. 